\title{
SPINA BIFIDA CYSTICA
}

\author{
BY
}

A. P. NORMAN, M.B., M.R.C.P., D.C.H.

\section{(From the Hospital for Sick Children, Great Ormond Street, London)}

A very large number of papers on the subject of meningoceles have been published since interest became really awakened in the middle of the last century. The majority of them are accounts of a few cases of an unusual type, or of a series of cases in which a particular operative technique has been used with an apparent improvement in the results; some of the papers are reviews of a large number of cases collected from various sources, and it is from these that most of the facts showing the general course of the disorder are obtainable.

In 1905 Moore published an analysis of some two hundred and fifty articles taken from the index catalogue of the surgeon general's office; it appeared from this that the mortality was over 35 per cent. following operation within the first few months of age, but was only 4.7 per cent. if operation was delayed till the age of four or five years. He concluded that the age of infancy and the presence of complications were contra-indications to operation; that all that a surgeon could hope to accomplish was removal of the unsightly tumour, although he mentioned a few cases where clubfoot or incontinence were reported to have been improved by operation.

Dandy and Blackfan (1914) suggested that the sac acted as an absorbing surface and that its removal upset the secretory equilibrium of the cerebrospinal fluid so that hydrocephalus resulted; this idea was restated by Harmer (1920) and Cutler (1924), who devised measures to preserve the sac wall at operation, but their operative mortality remained very high. Fraser (1929) reviewed the condition in a detailed and careful paper, suggesting a classification and operative technique. Penfield (Penfield and Cone, 1932; Penfield, 1935) emphasized that he considered that the sac provided an absorbing surface for cerebrospinal fluid, and so he retained the sac at operation; he gave an operative mortality of under 10 per cent. Gross and Sachs (1934) stated that the development of hydrocephalus was not common after operation if not already present. Kolodny (1933) claimed that the operative mortality might be reduced and described sixty cases in which there were three deaths after operation, nine neurological sequelae, and no hydrocephalus. He considered that there was no proof that operation was the cause of hydrocephalus, but that it was either present previous to operation or was a consequence of infection. Harrar (1937) found the incidence of spina bifida of all types to be about $1: 1,500$, in the records of confinements at the Lying-in Hospitals, New York, and stated that the results of operation gave no encouragement to alter the opinion that operation is of no value except in simple meningocele, uncomplicated in any way.

Russell and Donald (1935) broke new ground by their demonstration of the presence of the ArnoldChiari syndrome in a number of cases, which suggested a mechanism for the development of hydrocephalus in some instances. This paper, and that of Ingraham and Swan (1943) are really the only ones to produce any facts concerning the course of spina bifida since Moore's (1905) survey. Ingraham and Swan (1943), in a detailed survey of 546 cases of spina bifida and cranium bifidum, pointed out the weaknesses of their analysis, due both to incomplete records and to the lack of thorough post-mortem examinations. They concluded that the presence of a mass, in spina bifida, constituted an indication for operation in most cases, and that the age of choice for operation lay between twelve and eighteen months. They also considered that a progressing neurological disability was a strong argument for operation, on the grounds that growth caused increased tension on the anchored cord; and that a lipomatous growth might be pressing on the cord.

Little idea can be gained from any of the literature of the progress of any child with a specific type of meningocele which is left untouched. There is no positive evidence that a simple meningocele is harmful except in rare instances. Very few of the authors give any late results on cases that have been followed up after operation, and many fail to indicate what selection has been exercised in choosing the cases for operation. Statements showing the frequency with which the head was measured before operation are entirely missing in the discussions on hydrocephalus. It does appear, however, firstly that there is a very high mortality in spina bifida cystica in general with or without operation; secondly that operation on unselected cases is unlikely to reduce that mortality; thirdly that operation on cases of simple meningocele at any age has a low mortality and that after the age: of four years it is a fairly safe procedure. Finally, there is no reliable evidence in the whole of the literature that operation has ever saved a life; nor, except for Ingraham and Swan's ten cases, any 
reliable evidence that neurological symptoms have ever been relieved.

\section{Spina Bifida}

Survey of the literature shows that spina bifida cystica is sufficiently rare to make it difficult to form a large enough series from which any sound conclusions may be drawn, and yet sufficiently common to allow a number of dogmatic opinions to be formed on its course and proper treatment.

One hundred and sixty-one cases of spina bifida associated with a protruding sac have passed through the wards and out-patient departments of the Hospital for Sick Children between the years 1938 and 1947; I had hoped to find in this analysis some indication as to whether these children were benefited by operation or not, whether operation was ever in fact an emergency measure, and whether hydrocephalus was precipitated by operation. Partly because of a poor follow up, largely because essential facts were frequently missing from the notes, there is little to add to the facts already well known and described by Ingraham and Swan (1943) in their analysis.

These cases have been operated on by various surgeons whose ideas concerning the best time for operation and the best type of operation and even concerning the indications for operation are by no means the same and whose ideas may have altered during the ten years under review.

Of the 161 cases rather more than one-third are certainly living and rather more than one-third are certainly dead; of the remainder it is likely that the majority have also died. These figures, and those showing the frequency with which the sac was found in various sites, are similar to those published in other surveys (table 1). Congenital deformities of

TABLE 1

MORTALITY IN THE PRESENT SERIES

\begin{tabular}{|c|c|c|c|c|}
\hline & Total & Alive & Dead & Unknown \\
\hline $\begin{array}{ll}\text { Cranial } & \ldots \\
\text { Cervical } & \ldots \\
\text { Dorsal } & \ldots \\
\text { Lumbo-dorsal } \\
\text { Lumbar } & \ldots \\
\text { Lumbo-sacral } \\
\text { Sacral } & \ldots \\
\text { Sacro-coccygeal } \\
\text { Unknown }\end{array}$ & $\begin{array}{r}20 \\
4 \\
6 \\
9 \\
69 \\
17 \\
26 \\
1 \\
9\end{array}$ & $\begin{array}{r}11 \\
4 \\
3 \\
1 \\
27 \\
9 \\
11 \\
0 \\
1\end{array}$ & $\begin{array}{r}5 \\
0 \\
3 \\
4 \\
25 \\
6 \\
12 \\
1 \\
2\end{array}$ & $\begin{array}{r}4 \\
0 \\
0 \\
4 \\
17 \\
2 \\
3 \\
0 \\
6\end{array}$ \\
\hline 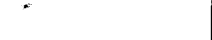 & 161 & 67 & 58 & 36 \\
\hline
\end{tabular}

the types commonly associated with spina bifida were found in the usual proportions and call for no comment.

Fate without operation. Seventy-four children were not operated on, and eighteen of these are known to have reached one year of age, but only ten were normal in every respect (except for the cyst) when last seen. Thirty are known to have died, mostly in the first few weeks of life, and of twenty-six the fate is unknown, but twelve of them were so grossly deformed as to make it likely that they died early, whilst only five of the remaining fourteen were without other abnormality. Thus, at most, only fifteen of the original seventy-four can have developed into normal children. Two sacs fibrosed and disappeared almost completely, leaving only a small fibrous knob, the one spontaneously and the other after rupture. It must be remembered that these figures give little direct information on the normal course of the whole group in the absence of operation, because they are formed for the most part from those cases in which operation was impossible or unlikely to be beneficial, and which, from the nature of their associated lesions, would have a bad prognosis.

Fate following operation. The cases which underwent operation form a selected group from which all the severely deformed and markedly paralysed children were excluded, so vitiating any direct comparison between the surgically treated and the remainder. Eighty-seven cases altogether were operated upon, eighty-three by excision or obliteration of the sac, three by suboccipital decompression, and one by simple incision of the sac.

Fifty-nine survived until they were at least one year old, and forty-one were living at the time of the survey, of whom thirty-one appeared to be physically and mentally normal; that is, 35 per cent. of those who underwent operation. The present series suggests that the likelihood of operative success increases after the first four weeks of life, the mortality before this age being almost double that which occurred later, and which remained more or less the same after the first month (table 2).

TABLE 2

RESULTS OF OPERATION

\begin{tabular}{l|c|c|c|c}
\hline \multicolumn{1}{c|}{ Age } & Total & Deaths & $\begin{array}{c}\% \text { of } \\
\text { total } \\
\text { opera- } \\
\text { tions }\end{array}$ & $\begin{array}{c}\% \text { of } \\
\text { group } \\
\text { opera- } \\
\text { tions }\end{array}$ \\
\hline 1 month and under . & 27 & 14 & $14 \cdot 9$ & 48 \\
6 months and under. & 28 & 6 & $6 \cdot 9$ & 21 \\
Over 6 months.. & 32 & 8 & 9 & 25 \\
\hline
\end{tabular}

The assessment of the best time for operation requires consideration not only of the operative mortality at various ages, but also of the natural mortality, and it can be seen that this is greater after the first month than before (table 3).

However, the increasing death rate with age largely reflects the dying off of the inoperable cases, and it certainly cannot be concluded that the danger of death in the uncomplicated case increases with age. A knowledge of the cause of death in every case, with or without operation, would show precisely whether meningocele was a surgical emergency requiring immediate intervention, but 
TABLE 3

RESULTS IN UNOPERATED CASES

\begin{tabular}{c|r|r|c}
\hline Age & Total & Deaths & $\begin{array}{c}\text { Deaths expressed } \\
\text { as \% of each } \\
\text { age group }\end{array}$ \\
\hline 1 month and under .. & 134 & 8 & 6 \\
6 months and under. & 98 & 11 & 11 \\
Over 6 months .. & 55 & 10 & 18 \\
\hline
\end{tabular}

this the notes lamentably fail to demonstrate. Rupture of the sac is known to have been the cause of death in only one case, but of course early operation may have prevented rupture or saved life in the case of a leaking sac in other cases. It is , notable how much more frequently infection of one type or another was the cause of death in the operated cases than in the non-operated (table 4).

TABLE 4

\section{CAUSES OF DEATH IN CASES WITH NO} HYDROCEPHALUS

\begin{tabular}{|c|c|c|c|c|}
\hline \multirow[b]{2}{*}{$\begin{array}{c}\text { No } \\
\text { operation }\end{array}$} & \multirow[b]{2}{*}{$\begin{array}{l}\text { Meningitis } \ldots \\
\text { Rupture of sac } \\
\text { Not connected } \\
\text { Inoperable } \\
\text { Cause unknown; no g }\end{array}$} & \multirow[b]{2}{*}{$\begin{array}{l}\cdots \\
\cdots \\
\cdots \\
\ldots\end{array}$} & \multirow[b]{2}{*}{$\begin{array}{l}\cdots \\
\cdots \\
\ldots\end{array}$} & No. \\
\hline & & & & $\begin{array}{l}1 \\
1 \\
1 \\
6 \\
5\end{array}$ \\
\hline & Total & . & . . & 14 \\
\hline Operation & $\begin{array}{l}\text { Meningitis } \\
\text { Leaking wound } \\
\text { Gastro-enteritis } \\
\text { Post-operative collaps } \\
\text { Encephalocele... } \\
\text { Not connected }\end{array}$ & $\begin{array}{l}\ldots \\
\cdots \\
\text { se } \\
\cdots \\
\cdots\end{array}$ & $\begin{array}{l}\cdots \\
\cdots \\
\cdots \\
\cdots\end{array}$ & $\begin{array}{l}8 \\
1 \\
3 \\
2 \\
1 \\
3\end{array}$ \\
\hline & Total & . & $\cdots$ & 18 \\
\hline
\end{tabular}

Neurological defects. No child suffering from paralysis of limb or sphincter appears to have been relieved in any respect by operation, and in eleven cases neurological lesions were a sequel of surgery; this includes none of those who died following operation. The presence of nerve tissue was noted in thirty-two and its absence in twenty-nine of the eighty-seven operated cases. Seventeen operations were performed on children already showing neurological lesions but without evidence of hydrocephalus, and eight died; some of these were severely deformed, so the figures can hardly be a reliable guide to the results of operation in those with slighter defects (table 5).

Hydrocephalus. Forty-two cases of hydrocephalus developed before operation, and only six of these are known to have survived to the time of this survey. There are three living from the group who did not undergo operation and all are grossly deformed; of seventeen who underwent surgery eight survived for the immediate postoperative
TABLE 5

\section{NEUROLOGICAL DEFECTS}

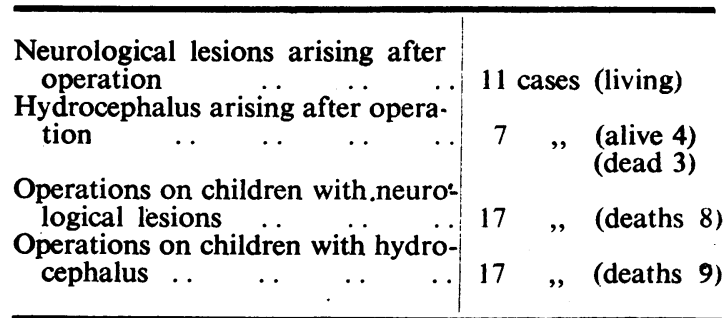

period but only three of these are quite normal. Hence the likelihood of death after operation seems greater in hydrocephalus than in the uncomplicated case, although it cannot be said that the prognosis for the hydrocephalic is made any worse by operation.

Seven children appeared to develop hydrocephalus after operation, but it is not certain that the heads were regularly measured before operation; the age of development of hydrocephalus was scattered over the first year, with most cases manifesting themselves in the first few months, whether with or without operation. It has long been held that excision of the meningocele can directly cause hydrocephalus, and whilst there is little published evidence to show that heads have ever been regularly measured before operation, there seems to be no doubt that rapidly increasing hydrocephalus may be precipitated by operation by stimulating the production of cerebrospinal fluid in some unknown way. A remarkable example of this was the child with a small pedunculated meningocele who developed a rapidly increasing hydrocephalus after operation; after over fifty lumbar punctures this subsided and she is today a normal child. No comment can be made on the frequency with which the Arnold-Chiari syndrome was found, nor on its association with hydrocephalus, owing to the small number of times in which this condition was sought during the period covered by this survey.

\section{Discussion}

These figures suggest that operation should not be performed until after the first month of life, owing to the heavy toll of meningitis and gastroenteritis following operation at this age; rupture of the sac has not been shown to be a frequent occurrence, and it is suggested that it does only occur in sacs with a raw, thin wall and a high tension of fluid, in children who are likely to have other gross defects (Denis Browne, personal communication). The prevention of rupture of the sac, and avoidance of infection of the cerebrospinal fluid, could be the only reasons for treating the condition as a surgical emergency. It is well known that the sac tends to toughen with age and to be protected by lipomatous growth. The balance of argument, therefore, is in favour of delaying operation.

Instead of the arrangement of spina bifida into groups according to the contents of the sac, it has 
TABLE 6

HYDROCEPHALUS: AGE OF ONSET

\begin{tabular}{l|c|c|c|c|c|c|c|c|}
\hline & Birth & $1-7$ days & $7-28$ days & $1-2$ months & $2-3$ months & 3-6 months & Over 6 months \\
\hline Pre-operative .. & 11 & 1 & 10 & 9 & 0 & 3 & 8 \\
Post-operative .. & & & 3 & 1 & 3 & \\
\hline
\end{tabular}

been suggested (Denis Browne, personal communication) that it might usefully be classified according to the nature of the developmental error: (1) a group with dura intact (spina bifida occulta); (2) a group with skin intact, but failure of fusion of dura (the fatty and pedunculated meningocele) ; (3) a group with failure of fusion of skin; (4) a group associated with hydrocephalus; (5) a group associated with failure of nerve formation; (6) a group associated with 'compression' defects such as arthogryposis and perhaps the Arnold Chiari syndrome.

(It must be noted that Coughlin (1931) states that he has confirmed Von Recklinghausen's findings of a dural defect in every case.)

It is the considered opinion of some of the surgeons at the Hospital for Sick Children that the operation is purely a cosmetic one and should be delayed until the child is old enough to survive the risks of hospital life. They would operate only on meningoceles of the pedunculated type or those with a small flat tissue paper surface (type 2).

The presence of any neurological defect would seem to be a contra-indication to operation until it can be shown in exactly which cases relief can be given, and until then the balance of argument from the literature and from the cases reviewed supports the idea that further harm rather than improvement is most likely to follow operation.

There are very few facts available concerning the development of hydrocephalus; the present series gives no information on its association with the Arnold-Chiari syndrome, nor can it be said definitely how many cases developed after operation and because of operation, nor are such facts available in the literature. The scattered distribution (table 6) of age of incidence rather suggests that operation acts only as a final stimulus in some way precipitating the rapid onset of hydrocephalus; it is in any case not invariably due to a pressure cone, nor to the Arnold Chiari syndrome. The older theory that the sac wall forms an absorbing area for lack of which hydrocephalus occurs seems highly improbable.

\section{Conclusions}

There is a remarkable lack of basic facts on which to form any judgment on the value of operation in particular instances, and on such things as the actual cause of death with or without operation; on the development of hydrocephalus; on the age. of development of the Arnold-Chiari deformity.

The results of the present series, and conclusions drawn from the literature in general, would suggest that operation should be delayed until after one year of age, and should be performed only on children showing no developing hydrocephalus and no neurological abnormalities. In at least 40 per cent. of such cases there is a chance of obtaining a normal child. It is clear, however, that there is no basis in fact for supposing that operation should be performed at all, except for purely cosmetic reasons. The lump is unsightly and may greatly distress the parents and later the child himself; the advantages of removing this must be weighed against the dangers of causing paralysis of sphincters or limbs, and even the risk of death. No relief of any other disability can be expected, although it is not impossible that in rare cases a nerve may be relieved from pressure or tension and improvement obtained. In centres where a sufficient number of cases are likely to be seen it would seem important to adopt a standard line of treatment or of operative technique, accompanied by thorough recording of the physical signs.

In this way the results of conservative and operative methods may be more accurately assessed; and, if a technique is eventually evolved by which damage to nerves is prevented, its value will be readily seen.

I wish to thank the surgeons of the Hospital for Sick Children for permission to make use of their cases, and Mr. Denis Browne and Dr. Martin Bodian for their helpful criticism.

\section{REFERENCES}

Coughlin, W. T. (1931). Ann. Surg., 94, 982.

Cutler, G. D. (1924). Arch. Neurol. Psychiat. Chicago, $12,149$.

Dandy, W. E., and Blackfan, K. D. (1914). Amer. J: Dis. Child., 8, 406.

Fraser, J. (1929). Edinb. med. J., 36, 284.

Gross, S. W., and Sachs, E. (1934). Arch. Surg., 28, 874.

Harmer, T. W. (1920). Bost. Med. Surg. J., 183, 775.

Harrar, J. A. (1937). Amer. J. Obstet. Gynec., 34, 661.

Ingraham, F. D., and Swan, H. (1943). New Engl. J; Med., 228, 559.

Kolodny, A. (1933). J. Amer. med. Ass., 101, 1626.

Moore, J. E. (1905). . Surg. Gynec. Obstet., 1, 137.

Penfield, W. V., and Cone, W. (1932). J. Amer. med. Ass., 98, 454.

(1935). Surg. Gynec. Obstet., 60, 363.

Von Recklinghausen (1886). Virchows Arch., 105, 243.

Russell, D. S., and Donald, C. (1935). Brain. 58, 203. 